\section{La salud en el Perú en tiempos del coronavirus: A reflexionar.}

\author{
Health in Peru in the time of coronavirus: To \\ reflect.
}

\author{
Jesus Lorenzo Chirinos-Cáceres '
}

Es premonitorio el haber tomado interés previamente en la descripción de cómo la corrupción afecta el sistema de salud y los demás sistemas en el Perú y el mundo, tema que nos lleva a reflexionar lo que está ocurriendo en el sistema de salud y sus efectos en otros sistemas en estos tiempos del coronavirus COVID-19 (SARS-CoV-2). ${ }^{1,2}$ Este es un tipo de virus ARN mutado y que pasó, aparentemente, de murciélago a humanos y que nos ha ocasionado más daño de lo que nosotros ocasionamos en la naturaleza. ${ }^{3}$ A la fecha se tiene mas de un millón de casos y mas de 58000 fallecidos en el mundo. ${ }^{4}$

El inicio de la pandemia ocurrió en China, en los meses finales del año 2019, y nuestra visión de lo global estuvo escotomizada, lo veíamos de manera lejana en espacio y tiempo, cuando debimos pensar que todo estaba mas cerca de lo que creíamos. El brote se extendió rápidamente en Wuhan por la contagiosidad del virus. Cada persona infectada contagiaba a 2 ó 3 personas, lo cual debía hacernos pensar en una curva de contagio exponencial. Sin embargo, al señalarse inicialmente que sus efectos eran leves en la mayoría ( 80 a $85 \%$ de los contagiados), con complicacines en el 10 a $15 \%$, siendo de gravedad en solo el 5\%, parecía no ser de mucha importancia. Aquí lo importante de resaltar es el crecimiento exponencial y la virulencia, para lo cual hay modelos matemáticos que lo explican y predicen. ${ }^{5}$

De pronto, en Wuhan se dieron cuenta que su sistema de salud iba a colapsar si seguía avanzando la epidemia, por lo que indicaron distanciamiento social, lo cual ya no fue suficiente y pusieron a todo Wuhan en cuarentena y aislamiento social, y ya todos sabemos lo que pasó luego allí y en toda China. Y, China llegó a controlar la epidemia, según lo que informan. ${ }^{6}$

La globalizacón permitió un crecimiento rápido de las condiciones económicas de los países e incrementó la

I Médico internista. Decano, Facultad de Salud Pública. Universidad Peruana Cayetano Heredia.
Chirinos-Cáceres JL. COVID-19: La salud en el Perú en tiempos del coronavirus: A reflexionar. Rev Soc Peru Med Interna. 20I9;33(I): I0-II. https://doi.org/10.36393/spmi.v33i1.504

movilidad social a moderadas y grandes distancias, por el gran movimiento de bienes y servicios a nivel global, así como las comunicaciones. Estas han permitido mantenernos al tanto de lo que ocurría en los diversos países con la entonces epidemia y ahora pandemia; sin embargo, continuábamos viendola como una situación lejana.

Conocido es lo que ha ocurrido en países de ingresos altos como Italia primero, luego España y Estados Unidos de Norteamérica, que se encontraban con afectados por debajo de China, y que en el momento actual lo han superado en número de casos y de fallecidos. Estados Unidos ha pasado al primer lugar e Italia se ha declarado en fase 4 de la pandemia. Actualmente, 194 países están involucrados. Aquí debo detenerme para señalar que estos países indicaban que sus sistemas de salud ocupaban puestos de primera línea en el mundo, pero la indiferencia y la soberbia, así como la falta de educación sanitaria (o en salud) e higiene en la población, los llevó a esas situaciones y a establecerse en ellos la pandemia. Esas situaciones son muy serias y de gran sufrimiento para la población en general y para los más vulnerables, en particular los varones mayores de 50 años, fumadores o con comorbilidad (hipertensión arterial, EPOC, diabetes mellitus, etc.). ${ }^{4}$

En el Perú, parece que las epidemias no nos enseñaron mucho. A pesar de los grandes esfuerzos realizados por nuestro sistema de salud, fragmentado, precario y con muy poca inversión, se pudo controlar una epidemia como la del cólera, donde estuvimos orgullosos de tener una mortalidad muy baja y el desarrollo de medios de rehidratación y cambios en la atención primaria que permitieron además establecer las unidades de rehidratación oral en las comunidades hasta la atención compleja con rehidratación parenteral oportuna y hemodiálisis pronta en los casos de insificiencia renal aguda. A partir de esa experiencia, los hechos nos llevaron a pensar en la universalización de la salud de manera progresiva, manteniendo fragmentado y precario el sistema de salud, y en un estado de corrupción a 
todo nivel que se prolongó hasta la actualidad.

Por otro lado, como veíamos la situación actual de manera lejana, no permitió evaluar y preparar nuestro sistema de salud de acuerdo a las experiencias dadas desde el momento en que se inició la pandemia, por estar mas absortos en los problemas de la política nacional y de las empresas inmersas en situaciones de corrupción. El tiempo que tuvimos pudo habernos llevado a reflexionar lo que ocurría en los países en mejor situación económica y de sistema de salud que afrontaban la epidemia. Por ejemplo, debimos integrar el sistema fragmentado para enfrentar la epidemia, ya que este virus afecta a todos por igual. Se debió coordinar para un trabajo conjunto entre el sector público y privado, así como con EsSalud y las Fuerzas Armadas; visualizar las necesidades de protección del personal de salud así como la implementación oportuna de las pruebas diagnósticas definitivas y complementarias; $y$, de equipos de acuerdo a los mayores efectos de la epidemia como camas hospitalarias y cuidados intensivos con equipos de respiración asistida. ${ }^{7}$ También, el uso de medicamentos, como antivirales e inmunomoduladores y plasma de convaleciente, que se han venido probando empíricamente sin mucha reserva, y con los cuales ya se están iniciando ensayos clínicos.

En cuanto a la población, educación sanitaria e higiene desde el inicio de la epidemia, con los pasos a seguir de acuerdo a las experiencias en China y otros países, las que debimos aprender con el cólera, SARS o MERS. Desde las más simples como lavarse las manos continuamente, no tocarse la cara, distanciamiento social, usar mascarilla y guantes, hasta las más complejas como cuarentena y aislamiento en vivienda (para casos leves y contactos sin cumplirse) y social, hasta llegar al toque de queda y el "pico y placa" por sexo, para lograr aplicarle dos "martillazos" a la curva evolutiva de contagio, de acuerdo a las fases de la epidemia. Pero, para ello se requiere un buen sistema de comunicación social a nivel local, regional y nacional, de lo que nuestros medios de comunicación masiva carecen. Tambén es importante que la población tome conciencia de lo serio del problema, aún cuando carezcan de educación sanitaria.

Felizmente, como decíamos mientras estudiábamos medicina, o cuando ya éramos médicos, que "Dios es peruano" o que "Aquí vive Dios", ante situaciones especiales que podían escaparse de nuestras manos y lográbamos revertir con iniciativa, creatividad e innovación de nuestros profesionales de la salud. Se ha logrado mantener la situación algo estable, a pesar de faltar pruebas diagnósticas, se ha acondicionado espacios para personas contagiadas con síntomas leves, pero hay escasez de implementos de protección y equipos necesarios.

Desde la detección del primer caso de COVID-19, el 6 de marzo, se han ido estableciendo medidas a nivel del sistema de salud y poblacional. Es así que, luego de 28 días de iniciado nuestro drama, podemos decir que se ha yugulado en parte la epidemia. ¿Cómo? Siguiendo los pasos a nivel poblacional: lavarse las manos, distanciamiento y aislamento (en vivienda y social) por la gran movilidad de personas que existe dadas las condiciones de trabajo tanto formal como informal y los medios de transporte masivos que se disminuyeron, así como el cierre del aeropuerto. Luego, estableciendo la emergencia sanitaria nacional, la cuarentena y cierre de fronteras en el país y el toque de queda al inicio de la noche, ampliado en algunas regiones, aunque con algún retraso, pero todavía a tiempo, lo que se refleja no en el número de casos en las 21 regiones comprometidas al 2 de abril, que llega a 1595 casos, contando con muy pocos profesionales de la salud, luego de 17334 pruebas realizadas, que son pocas, sino en el número de hospitalizados (243 casos), los internados en unidades de cuidados intensivos con ventilación mecánica (72 casos), y los decesos en número de 61, que terminaron solos y cremados), lo que nos pone en el mundo en el segundo lugar de logros en corto tiempo. Sin embargo, vienen tiempos muy difíciles para nuestro sistema de salud, de educación, agroalimentario y económico, en general. Un simple virus nos ha confinado y está ayudando al planeta a recuperarse, con un costo humano, social y económico muy grande. Roguemos que la vacuna salga pronto y que Dios nos proteja.

Finalmente, nuestro agradecimiento más profundo a nuestros profesionales de salud, y personal de salud en general, que a pesar de las condiciones vienen enfrentando la pandemia con altura. Esperemos que luego de este episodio difícil, el sistema de salud entre en reestructuración verdadera y que las condiciones de trabajo estén dentro de las normas técnicas nacionales e internacionales y los aspectos éticos, y que la corrupción sancionada, en especial en el tiempo de emergencia nacional, con todo el rigor de la ley.

\section{REFERENCIAS BIBBLIORÁFICAS}

I García PJ. Corruption in global health: the open secret. Lancet. 2019 Dec 7;394(I02I4):2II9-2I24. doi: 10.10I6/S0I40-6736(I9)325279. Epub 2019 Nov 27.

2. Chirinos-Cáceres, J L. Editorial. La corrupción en el sector salud: ¿A quién afecta? Rev Soc Peru Med Interna. 2019;32(4): I 25-126. https:// doi.org/I0.36393/spmi.v32i4.489

3. Sociedad Argentina de Medicina (SAM) y Foro de Medicina Clínica Argentina (FMC). Recomendaciones para la asistencia integral de los pacientescon infecciones potenciales por COVID-19, desde los cuidados prehospitlarios a la atención en Emergencia y en pacientes hospitalizados. 0 I de abril 2020; $\mathrm{p} 6$.

4. Zhao X, Zhang B, Li P, Ma C, Gu J, Hou P, et al. Incidence, clinical characteristics and prognostic factor of patients with CVID-19: a systematic review and meta-analysis. Preprint MedRxiv DOI: https:/ doi.org/l 0.I I0I/2020.03.1720037572

5. Apoyo Consultoría. Predicción de casos confirmados del COVID-19 en el Perú. Informe al 3 I de marzo. Lima, Banco Central de Reserva del Perú; 2020. pp:2- 12.

6. Chen S, Zhang Z,Yang J,Wang J, Zhai X, Bärnighausen T, et al. Fangcang shelter hospitals: a novel concept for responding to public health emergencies. The Lancet. URL disponible en: https://doi.org/10.1016/ SOI40-6736(20)30744-3

7. Wölfel R, Coorman V,Wolfgang G, Seilmaier M, Zange S, Müller M, et al. Virological assessment of hospitalized patients with COVID-2019. Nature. URL disponible en: https://doi.org/10.1038/ s4I586-020-2196-x(2020) 